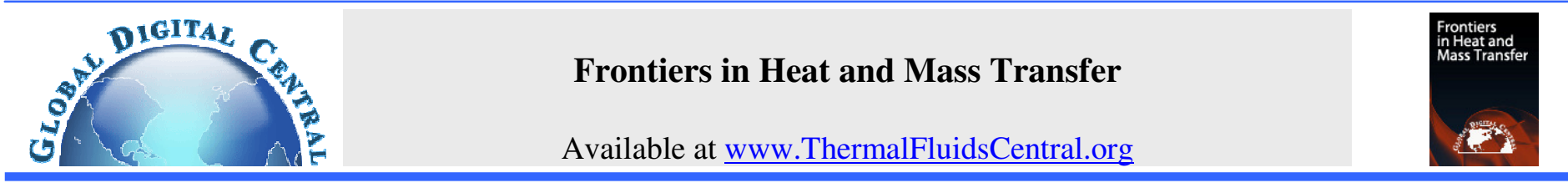

\title{
RADIO FREQUENCY HEATING OF IMPLANTED TISSUE ENGINEERED SCAFFOLDS: SIMULATION AND EXPERIMENTAL STUDIES
}

\author{
Mohammad Izadifar, ${ }^{\mathrm{a}, \mathrm{b}^{*}}$ Xiongbiao Chen $\mathrm{e}^{\mathrm{a}, \mathrm{b}}$ \\ ${ }^{a}$ Division of Biomedical Engineering, College of Engineering, University of Saskatchewan, Saskatoon, SK, S7N 5A9, Canada \\ ${ }^{b}$ Department of Mechanical Engineering, College of Engineering, University of Saskatchewan, Saskatoon, SK, S7N 5A9, Canada
}

\begin{abstract}
Heat can be potentially used for accelerating biodegradation of implanted tissue engineered scaffolds. Cyclic and continuous radio frequency (RF) heating was applied to implanted chitosan and alginate scaffolds at 4 applied voltages, 3 frequencies, and 2 thermally conditioning environments. A $3 D$ finite element model was developed to simulate the RF treatment. A uniform RF heating was achieved at the scaffold top. For alginate, voltage was the only significant $R F$ heating factor while both frequency and voltage significantly affected RF heating of chitosan. Less temperature gradient across the scaffold was achieved at a conditioning environment at $<30^{\circ} \mathrm{C}$. Surrounding tissue was insignificantly affected by RF heating of scaffolds.
\end{abstract}

Keywords: Heat transfer, radio frequency heating, tissue engineering.

\section{INTRODUCTION}

The dramatic advancements in the field of tissue engineering within the last decade suggest the potential for regenerating almost every tissue and organ of the human body (Dhandayuthapani et al., 2011). The main goal in tissue engineering is to restore, maintain, or improve defective or lost tissue functions either by developing biological substitutes or by i) implanting isolated cells in the organism; ii) delivering growth factors and tissue stimulating substances to the defective tissue/organism, or iii) seeding cells on or within a biocompatible/degradable porous scaffold and implanting the scaffold in the damaged tissue (Langer and Vacanti, 1993). The later strategy is associated with scaffold based tissue engineering in which the seeded cells proliferate, migrate and differentiate into the specific tissue while cells are secreting the required extracellular matrix components for generating the tissue and the scaffold is degrading. Scaffold degradation basically refers to the loss of the material leaving the scaffold mass in the course of cell culture on/into the scaffold and during tissue formation after implantation.

Biodegradability is one the most critical characteristics of a scaffold such that a scaffold with an inappropriate degradation rate can lead to the failure of tissue engineering therapy. When a scaffold is implanted in the body, it will be subjected to a mechanical load and biochemical/physical conditions influencing the scaffold degradation rate. The degradation rate of the scaffold must match the rate of new tissue formation; otherwise, too slow or too fast degradation will result unsatisfactory tissue engineering therapy. If the scaffold implanted in a load bearing area of the body degrades too quickly, a significant decrease in mechanical properties of the scaffold can cause the scaffold to lose its supportive structure in the absence of well tissue formation within the scaffold construct (Blitterswijk et al., 2008). On the other hand, if the scaffold degradation rate is too slow, it prevents a well tissue formation within the scaffold. Therefore, one of the keys in successful scaffold based tissue engineering is the synchronization between the scaffold degradation and the tissue formation indicating the significance of controlling of the scaffold degradation during tissue regeneration for a reliable tissue engineering therapy.

Once the scaffold is implanted in the tissue, the biological environment of the tissue takes control over the biodegradation of the scaffold such that our control over synchronizing the scaffold biodegradation with the tissue regeneration becomes extremely limited. However, if one of major factors affecting the scaffold degradation can be adjusted, theoretically the biodegradation should be adjustable accordingly. In addition to several physical and chemical factors such as scaffold porosity and pore size, composition, cellular and enzymatic activity, and $\mathrm{pH}$, scaffold degradation can be influenced by thermal activation, oxidation and hydrolysis (Gopferich, 1996). Hydrolysis is the most important degradation reaction in which ester hydrolysis of polymer compounds occurs by the reaction of water with ester bond (Blitterswijk et al., 2008). The hydrolysis of an absorbable polymer is a function of many factors, both material-related and implant-site-related, including temperature. Pietrzak et al. (2003) conducted an in vitro study to investigate the influence of temperature on hydrolysis and found that a variance from $37^{\circ} \mathrm{C}$ to as little as $2{ }^{\circ} \mathrm{C}$ can affect the rate of hydrolysis of a PGA/PLLA copolymer about 25-30\%, with the rate increasing with increasing temperature (Pietrzak et al., 2003). Also, Bergsma et al. (1995) predegraded three absorbable polymers: poly(L-lactic acid), crosslinked poly(L-lactic acid), and a copolymer of 4:96 poly(D,Llactic acid) at elevated temperature before animal implantation to reduce the in vivo residence times required to substantially degrade these materials (Pearce, 1986). Therefore, heat, which is basically one of the forces influencing rates of chemical reactions can be employed to influence the reaction rate of hydrolysis causing the scaffold biodegradation while the tissue regeneration is occurring within the scaffold. 
Radiofrequency (RF) heating has been an emerging heating technology which has been used for different biomedical applications. RF energy assisted surgery has been successfully used for cauterizing, coagulating, cutting and fulgurating tissues, and recently for ablating tumors (Panescu et al., 1995). RF-based instruments have allowed for treatments of seizure foci within the brain, aberrant conduction pathways within the heart, hypertrophic prostate tissue, and flaccid or redundant soft tissue of nasal conchae, palate, and tongue base (Morady, 1999; Li et al., 1998; Powell et al., 1998; Haesendonck et al., 1998; Keefe, et al., 1999). Most of clinical RF applications use microprocessors allowing for precise control of heat generation in the tissue surrounding the RF electrodes (Choi and Konrad, 1999). In addition to clinical applications, RF heating has been shown to effectively reshape cartilage while maintaining cellular viability, implying another novel application of RF heating technology (Choi and Konrad, 1999).

To the best knowledge of the authors of this article, application of RF-induced heating has not been attempted as a potential approach for adjusting the temperature of an implanted scaffold. This study investigates the feasibility of the idea of applying radio frequency (RF) assisted heating for adjusting the temperature of implanted biodegradable scaffolds. Since the biodegradation is a function of temperature, RF-induced heating of the scaffold can enable us to adjust the scaffold temperature which eventually leads us to predict the in situ biodegradation of the implanted scaffold aiming a feedback control system of biodegradation. To achieve this goal, experiments should be conducted to demonstrate the feasibility of the RF assisted heating in increasing the temperature of implanted scaffolds. Since RF power dissipation in a scaffold highly depends on the composition of the scaffold, the RF-induced heating rate can significantly vary from a scaffold to another. In order to candidate a potentially well suited biomaterial/polymer composition for RF-induced heating of the scaffold, it is essential to investigate the influences of different tissue engineering biomaterials and polymers (i.e. Chitosan, PLGA, PLA) and their constituting fractions on the RF heating rate of the scaffold.

The main objective of this study is to theoretically and experimentally perform thermal analyses associated with RF energy deposition in implanted scaffolds and the surrounding tissue during RFinduced heating treatments. Different treatment conditions including different frequencies, RF electric fields and treatment patterns (continuous and cyclic) at normal tissue temperature and pre-cooled tissue conditions were applied to the RF heating treatment. Based on multivariable statistical analyses at a significant level ( $p$ value) of 0.01 , the treatment variables which significantly affected the scaffold and the surrounding tissue temperatures as well as the RF energy deposition rate in the scaffold were identified. In addition, the effect of the initial tissue temperature on the surrounding tissue temperature elevation and temperature gradient across the scaffold during the RF treatment was investigated. Theoretical analyses were performed by conducting multiphysics three dimensional simulation of RF induced heating of implanted scaffolds. The model was validated using the observations at different conditions of the RF heating treatment. The model was used for sensitivity analyses of the RF heating performance with respect to the scaffold electrical conductivity which can be adjusted during the scaffold fabrication.

\section{MATERIALS AND METHODS}

Ideally RF heating of an implanted scaffold should increase the scaffold temperature uniformly within a short period of time with minimum heat exposure to the surrounding tissue. When RF is applied, the scaffold and the tissue temperatures start increasing. RF heating in biological tissues is mainly based on molecular frictions due to either ionic oscillation or flip-flop rotation of molecules (mainly water molecules) depending on the applied frequency. RF-heating rate in the scaffold and tissue strongly depends on the applied electric field, frequency, and dielectric properties. The properties of the tissue mimicking phantom, which was used in this study for more precise observation and instrumentation during the experiments, possesses similar electrical properties to the human tissue. In addition to the above parameters, the $\mathrm{RF}$ exposure time, the initial temperature, and the desired treatment temperature have important roles in RF heating treatment outputs. In this study, two RF heating treatment fashions, cyclic and continuous treatments, at a fixed treatment temperature of $45^{\circ} \mathrm{C}$ were used in order to distinguish the difference between these two methods in terms of RF heating patterns in the scaffold and the surrounding tissue.

\subsection{Scaffold Fabrication}

A splittable model containing three identical cells and a cavity housing calcium chloride solution was made of delrin. Three cells with radius and heights of 5 and $20 \mathrm{~mm}$, respectively, were filled with the same volume of $3 \%(\mathrm{w} / \mathrm{v})$ alginate followed by filling the cavity above the cells with $30 \mathrm{mM}$ calsuim chloride. After 24 hours at room temperature, alginate scaffolds were retrieved by splitting the mold and stored in calcium chloride solution of $30 \mathrm{mM}$ at $5^{\circ} \mathrm{C}$ for $\mathrm{RF}$ treatment experiments.

Chitosan solution $(4 \% \mathrm{w} / \mathrm{v})$ was prepared by rapid mixing $(600$ $\mathrm{rpm}$ ) of low molecular chitosan (Sigma Aldrich) in 1\% v/v acetic acid at room temperature. To enhance the scaffold electrical conductivity, $2 \% \mathrm{w} / \mathrm{v}$ sodium chloride ( $99.5 \%$ purity) was added to the chitosan solution and stirred until a homogenous solution was obtained. Molds $(5 \times 5 \times 20 \mathrm{~mm})$ were filled by the solution and were frozen at $-30^{\circ} \mathrm{C}$ overnight. Using a freeze drier (Labconco Co., MO) samples were immediately freeze-dried for 2 days at $-50^{\circ} \mathrm{C}$ and 0.1 mbar pressure. Scaffolds were retrieved from the molds, and the desirable sample height of $12 \mathrm{~mm}$ was obtained by cutting off the sample height for RF experiments. Scaffolds were stored in room temperature before being used for experiments. Chitosan scaffolds were soaked by saline at $8 \%$ w/v concentration before being used for experiments.

\subsection{Tissue Mimicking Phantom Preparation}

The tissue-mimicking phantom included polyacrylamide, bovine serum albumin (BSA) the protein used as a temperature-sensitive indicator, and glycerol. The phantom has several merits such as stability in high temperatures $\left(50-100^{\circ} \mathrm{C}\right)$, solid form to avoid convection heat transfer during thermal treatments, high transparency in room temperature, chemically and physically long time stability, three-dimensional visualization of heating area due to BSA coagulation, easy preparation, and similar thermal and electrical properties as human tissues (Mcdonal et al., 2004; Bu-Lin et al., 2008). BSA (1.5\% w/v) (Sigma-Aldrich) was dissolved in $0.02 \mathrm{M}$ citrate buffer consisting of citric acid monohydrous $(0.154 \% \mathrm{w} / \mathrm{v})$ and citrate tribasic dehydrate $(0.373 \% \mathrm{w} / \mathrm{v})$. Acrylamide with the concentration of $8.5 \% \mathrm{w} / \mathrm{v}$ was stirred in the citrate buffer at $900 \mathrm{rpm}$ followed by adding and stirring N, N-methylene-bisacrylamide at the concentration of $0.4 \% \mathrm{w} / \mathrm{v}$ until the dissolution was completed. Then, glycerol with the volumetric fraction of $4 \% \mathrm{v} / \mathrm{v}$ was added to the solution at a mixing rate of $500 \mathrm{rpm}$ followed by storing the solution at $2^{\circ} \mathrm{C}$.

The phantom $\mathrm{pH}$ can be adjusted according to the desired turbidity temperature associated with BSA coagulation temperature. L-ascorbic acid, $1 \% \mathrm{FeSO}_{4}$, and $3 \% \mathrm{H}_{2} \mathrm{O}_{2}$ were used as the initiator-activator pairs. Due to quick polymerization, the solution was immediately transferred to the mold to avoid air bubbles in the phantom followed by storing the phantom at $4-5^{\circ} \mathrm{C}$ for at least 2 hours before being used for experiments.

\subsection{RF Heating Apparatus and Experimental Design}

Figure 1 depicts the schematic diagram of the apparatus used for RF heating of scaffolds implanted in the tissue mimicking phantom. A cylindrical tissue mimicking phantom retainer with a radius and height of 25 and $100 \mathrm{~mm}$ was used to contain the phantom during the experiment. Three sampling ports with diameter of $2 \mathrm{~mm}$ each were allocated to fiber optic temperature sensors along the height of the retainer wall. The upper first and second fiber optic sensors were placed 


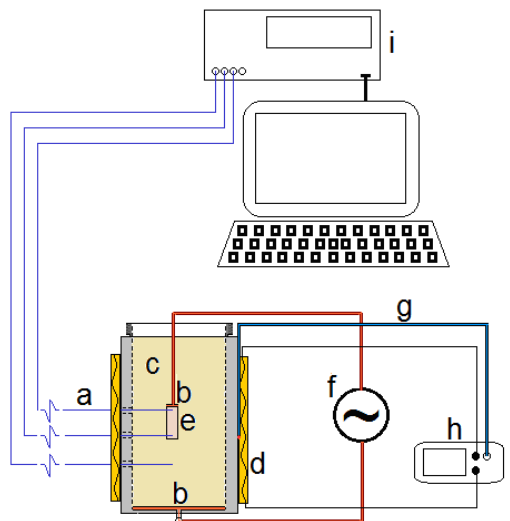

a: Fiber optic sensor

b: RF electrode

c: Tissue phantom

d: Thermoelectric blanket

e: Scaffold

f: RF generator

g: Temperature sensor

h: Temperature controller

i: Data logger

Fig. 1 Schematic diagram of RF heating apparatus.

at a $1 \mathrm{~mm}$ distance from the scaffold top and bottom, respectively. The clearance between the first and the second sensor was $10 \mathrm{~mm}$. The third port was allocated placed at $10 \mathrm{~mm}$ distance from the implanted scaffold bottom. The ground electrode with a diameter and thickness of 50 and $1 \mathrm{~mm}$ was placed at the bottom of the phantom retainer.

Inserting the first and the second sensors into the scaffold, the scaffold was vertically held straight upward in the container. After setting the third temperature sensor at $10 \mathrm{~mm}$ below the scaffold, 180 $\mathrm{ml}$ of the phantom solution (see sec. B) at $5^{\circ} \mathrm{C}$ was mixed with gel initiators and immediately was transferred into the container. Then RF electrode was deployed at the top of the scaffold surface and the entire container was kept in refrigerator at $5^{\circ} \mathrm{C}$ over night for a complete phantom gel formation.

A full factorial experimental design including three frequencies $(3.5,13.56$, and $27.12 \mathrm{MHz})$ and four level of applied voltage $(30,35$, 40 , and $52 \mathrm{~V}$ ) in two different RF treatment fashions, continuous and cyclic treatments, at a treatment temperature set point of $45 \pm 0.1^{\circ} \mathrm{C}$. The continuous RF treatment was performed for 5 minutes, and the cyclic treatment was conducted at 5 cycles with a $90 \mathrm{~s}$ treatment time at $45^{\circ} \mathrm{C}$ and a resting temperature of $37^{\circ} \mathrm{C}$ between cycles. Experiments were conducted at two levels of thermally conditioned environments which were a cooling environment providing an initial phantom and scaffold temperature below $30^{\circ} \mathrm{C}\left(22-27 \pm 3^{\circ} \mathrm{C}\right)$ using an air conditioner, and the body temperature environment at $37^{\circ} \mathrm{C}$ using a thermoelectric blanket. Before starting the experiments at cooling environment, the apparatus including container, phantom and sensors were transferred to an air conditioning room at $22 \pm 3^{\circ} \mathrm{C}$ and were given 5 hours to reach thermal equilibrium.

For the case where the equilibrium temperature was body temperature, the container wall was covered by a thermoelectric blanket with a sensor to set the phantom temperature at $37^{\circ} \mathrm{C}$ during the experiments (see Fig. 1). Then, fibre optic sensors were connected to a data logger for monitoring temperatures during experiments. The ground and RF electrodes were connected to an AC generator set-up capable of providing a range of voltage up to $100 \mathrm{~V}$ at frequencies between 3.5 to $30 \mathrm{MHz}$.

\subsection{Statistical Analysis}

Experimental data were used for calculating the required variables including heating rate, temperature gradients, and maximum tissue phantom temperature elevation. RF heating rates were obtained from the slope of the linear regression line with the least mean squared error over the data of the first heating ramp immediately after applying RF field to the scaffold. Multivariable statistical analyses were conducted using SPSS software at a significance level of 0.01 (p-value $<0.01)$ to identify variables having significant effects on RF heating of scaffold and the tissue. Multiple regression equations statistically describing the variation of tissue temperature rise and $\mathrm{RF}$ heating rate in alginate and chitosan scaffolds were also obtained from the collected data.

\subsection{Simulation}

COMSOL (Comsol Multiphysiscs Version 4.2) was used for developing a three dimensional finite element model of RF heating of the scaffolds implanted in the tissue phantom. The governing equations included electromagnetic and heat transfer partial differential equations needed to be solved simultaneously. The applied electric field at any points inside the phantom and the scaffold is governed by a quasi-static approximation of Maxwell's equations as (Choi and Konrad, 1991):

$-\nabla .\left(\left(\sigma+j 2 \pi f \varepsilon_{0} \varepsilon^{\prime}\right) \nabla V\right)=0$

where $j$ is $\sqrt{-1}, \sigma$ is the electrical conductivity $\left(\mathrm{Sm}^{-1}\right), f$ is frequency $(\mathrm{Hz}), \varepsilon_{0}$ is the relative permittivity of the vacuum, $\varepsilon^{\prime}$ is the relative dielectric constant, $V$ is the electric potential $(\mathrm{V})$, and $-\nabla V$ is the applied electric field, $E,\left(\mathrm{Vm}^{-1}\right)$. The heat transfer at any point inside the tissue and scaffold is governed by the transient conductive heat transfer as:

$$
\rho C_{p} \frac{\partial T}{\partial t}=\nabla(k \nabla T)+Q_{R F}
$$

where $\rho$ is the density $\left(\mathrm{kgm}^{-3}\right), C_{p}$ is the specific heat capacity $\left(\mathrm{Jkg}^{-1} \mathrm{~K}^{-}\right.$ $\left.{ }^{1}\right), T$ is the temperature $\left({ }^{\circ} \mathrm{C}\right), t$ is time (s), $k$ is thermal conductivity $(\mathrm{Jm}$ $\left.{ }^{1} \mathrm{~K}^{-1} \mathrm{~s}^{-1}\right)$, and $Q_{R F}\left(\mathrm{Wm}^{-3}\right)$ is the heating rate associated with $\mathrm{RF}$ energy dissipation inside the tissue and scaffold and is defined as:

$Q_{R F}=2 \pi f \varepsilon_{0} \varepsilon^{\prime \prime}|E|^{2}=\sigma|-\nabla V|^{2}$

where $-\nabla V$ is obtained from Eq. (1) which performs as the coupling equation of Eqs. (2) and (3) for computing the time dependent temperature distribution across the tissue and the scaffold. For simplicity, it is assumed that specific heat capacity, thermal conductivity and dielectric properties of the tissue and scaffold remain unchanged within the temperature range between 20 to $50^{\circ} \mathrm{C}$. Defining boundary conditions, a source voltage $(30-52 \mathrm{~V})$ was specified to the deployed RF electrode and the boundary condition of ground $(V=0)$ was applied to the ground electrode. The electrical insulating boundary condition $(-\sigma \nabla V=0)$ was applied to the outer surfaces of the phantom and to the top surface of the deployed electrode. The continuity boundary condition was used for the interior surfaces of the scaffold except for the deployed electrode where the top surface of the scaffold was subjected to the source of voltage. Thermal insulating boundary condition $(-k \nabla T=0)$ was applied to the top and bottom surfaces of the phantom while the outer circumferential surface was set at fixed temperatures according to the cooling environment or body temperature condition. Heat transfer continuity boundary condition was used for the exterior surfaces of the scaffold.

Physics-controlled mesh option (fine mesh) provided by Comsol Version 4.2 was used for meshing the solution domain. Time dependent solver of BDF with an absolute tolerance of 0.001 was used for solving the systems of equations. The electrical and thermal properties of the phantom and the electrode (copper) used for the finite element simulation of RF heating are given in Table 1. Since the water dominates $(\sim 97 \%)$ in the composition of the alginate and chitosan scaffold, water thermal properties was used for the scaffold properties.

Simulation was performed for different applied frequencies and applied voltages according to experimental conditions. Simulation post processing was performed in order to visualize and extract time dependent predicted values of electric field and temperature of the scaffold and the tissue phantom at different RF heating conditions. In order to validate the model, simulation results were statistically compared to the experimental values at the same operating conditions, and then the agreement between observations and predictions were 
assessed based on root mean squared error (RMSE), mean squared error (MSE) and coefficient of determination $\left(\mathrm{R}^{2}\right)$.

\section{RESULTS AND DISCUSSION}

Figure 2 illustrates the variation of temperature of the scaffold and the phantom at different locations with respect to time at initial temperatures of $25^{\circ} \mathrm{C}$ (a) and $37^{\circ} \mathrm{C}(\mathrm{b}, \mathrm{c})$ for periodic $(\mathrm{a}, \mathrm{b})$ and continuous treatments (c). As seen in Fig. 2a, for the RF treatment with cooling condition, the phantom temperature is initially less than $30^{\circ} \mathrm{C}$. When RF field is applied, the scaffold temperature at the scaffold top starts increasing with significantly higher rate than that at the scaffold bottom. This is associated with the larger RF electric field at the scaffold top than that at the scaffold bottom. Since RF heating rate is a function of squared RF electric field (see Eq. (3)), the higher induced RF heating rate at the scaffold top, where larger RF electric field exists, is larger than that at the scaffold bottom. As seen in Fig. 2a, RF is turned on/off to maintain the temperature at the scaffold top at $45^{\circ} \mathrm{C}$ for $90 \mathrm{~s}$ during which the temperature of the scaffold bottom keeps rising due to RF heating as well as heat conduction from the upper scaffold levels possessing higher temperature. The phantom temperature below the scaffold increases with time; however, due to the lower dielectric loss factor and lower electric field in the phantom, RF heating rate in the phantom below the scaffold is lower than that in the scaffold. Therefore, the main mechanism of the temperature increase in the tissue phantom surrounding the scaffold is heat conduction particularly because the phantom has an initial temperature of $<30^{\circ} \mathrm{C}$ which provides a $15^{\circ} \mathrm{C}$ temperature difference as a sufficiently high driving force for heat conduction from the scaffold to the phantom. After $90 \mathrm{~s}$, a resting time, during which RF is turned off, is given to the scaffold until the scaffold top temperature reaches $37^{\circ} \mathrm{C}$ followed by starting the next cycle of RF exposure. The cyclic treatment was considered for avoiding continuous heating exposure to the cells for the cases where cells are incorporated in the scaffold. As it can be seen, RF exposure continues until the scaffold top temperature reaches $45^{\circ} \mathrm{C}$ again. During the treatment, the temperature of the scaffold bottom gently rises and reaches $37.4^{\circ} \mathrm{C}$ after 5 cycles of the treatment while the tissue phantom temperature experiences a slight increase up to $33^{\circ} \mathrm{C}$

Figure $2 \mathrm{~b}$ shows a 5 cycle RF treatment of chitosan scaffold at body temperature $\left(37^{\circ} \mathrm{C}\right)$ condition. Since the scaffold composition remains unchanged, RF heating rate at the scaffold top is the same as that in the first treatment described for Fig. 2a. However, because the initial temperature of the scaffold is $37^{\circ} \mathrm{C}$, RF exposure time for increasing the scaffold temperature to $45^{\circ} \mathrm{C}$ is significantly less than

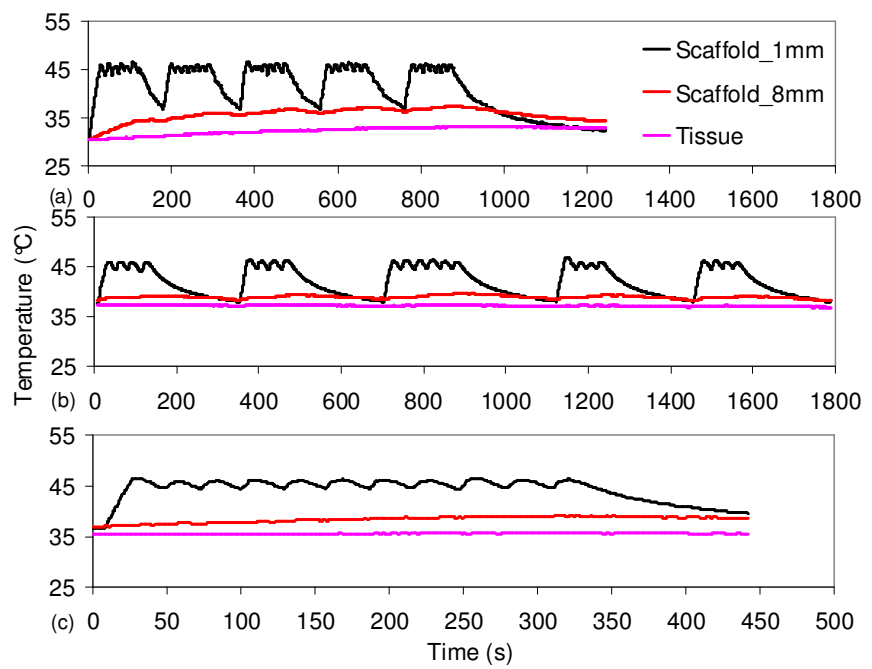

Fig. 2 Chitosan scaffold and phantom temperatures vs. time for cyclic $\mathrm{RF}$ treatments at $27.12 \mathrm{MHz}, 40 \mathrm{~V}$ and initial temperatures of $30^{\circ} \mathrm{C}$ (a), $37^{\circ} \mathrm{C}$ (b), and for continuous RF treatment at 13.56 $\mathrm{MHz}, 30 \mathrm{~V}$ and initial temperature of $37^{\circ} \mathrm{C}(\mathrm{c})$. that for RF treatment with cooling condition. Therefore, the tissue phantom is exposed to less RF heating time leading to very slight temperature increase in the phantom during the entire RF treatment. Due to the smaller temperature difference between the tissue phantom $\left(37^{\circ} \mathrm{C}\right)$ and the scaffold top $\left(45^{\circ} \mathrm{C}\right)$, the rate of heat conduction for body temperature condition is smaller than that for cooling condition in which the phantom was constantly surrounded by a cooling environment at $<30^{\circ} \mathrm{C}$. Therefore, lower heat transfer from the scaffold top causes a longer resting time needed for the scaffold top to reach $37^{\circ} \mathrm{C}$ before $\mathrm{RF}$ is re-applied. Therefore, the entire RF treatment takes longer time compared to the RF treatment with cooling condition (see Figs. 2a and b).

Figure $2 \mathrm{c}$ depicts a 5-minute continuous RF treatment at 13.56 $\mathrm{MHz}$ and $30 \mathrm{~V}$ for the initial temperature of $37^{\circ} \mathrm{C}$. As seen, the chitosan scaffold bottom temperature keeps rising during the treatment while the scaffold top temperature is adjusted at $45^{\circ} \mathrm{C}$ by controlling the RF exposure. While the scaffold bottom temperature increases up to $39^{\circ} \mathrm{C}$, the surrounding temperature remains at the initial temperature in the entire treatment due to the thermoelectric blanket providing a constant temperature of $37^{\circ} \mathrm{C}$ across the phantom. In other word, the cooling effect of the blood perfusion leading to constant tissue temperature $\left(37^{\circ} \mathrm{C}\right)$ in the body can be performed by the thermoelectric blanket kept the surrounding phantom temperature at $37^{\circ} \mathrm{C}$ in this study.

Observations indicated that for body temperature condition $\left(30^{\circ} \mathrm{C}\right)$ where the thermoelectric blanket was on, the tissue phantom temperature increased as low as $1^{\circ} \mathrm{C}$ at all applied voltages; however, for a cooling condition $\left(<30^{\circ} \mathrm{C}\right)$, the $\mathrm{RF}$ treatment led to a tissue phantom temperature rise of $5.5^{\circ} \mathrm{C}$. In addition, when the applied voltage was decreased from 52 to $30 \mathrm{~V}$, the phantom temperature increased as well. It was attributed to the longer RF exposure time required at lower voltages for increasing the scaffold temperature from $<30^{\circ} \mathrm{C}$ to the set point of $45^{\circ} \mathrm{C}$. Therefore, the longer RF exposure time induced more RF heating causing higher phantom temperature. Temperature gradient across the scaffold can be another assessing measure of RF heating. The temperature gradient can be defined as $\left(T_{f^{-}}\right.$ $T) /\left(T_{f}-T_{i}\right)$ where $T_{f}$ is the final temperature (e.g. $45^{\circ} \mathrm{C}$ ) at the scaffold top, $T$ is the scaffold temperature at the scaffold bottom, and $T_{i}$ is the initial temperature. As seen in Fig. 3, the dimensionless temperature gradient characteristic for RF treatment at initial temperature of $<30^{\circ} \mathrm{C}$ is smaller than that for the RF treatment at $37^{\circ} \mathrm{C}$ for all levels of voltages. Because scaffolds with initial temperatures of $<30^{\circ} \mathrm{C}$ need more $\mathrm{RF}$ exposure time to reach $45^{\circ} \mathrm{C}$, more $\mathrm{RF}$ heating across the scaffold is resulted. It indicates that a scaffold at an initial temperature of $<30^{\circ} \mathrm{C}$ can gain more heat at the lower part of the scaffold during RF

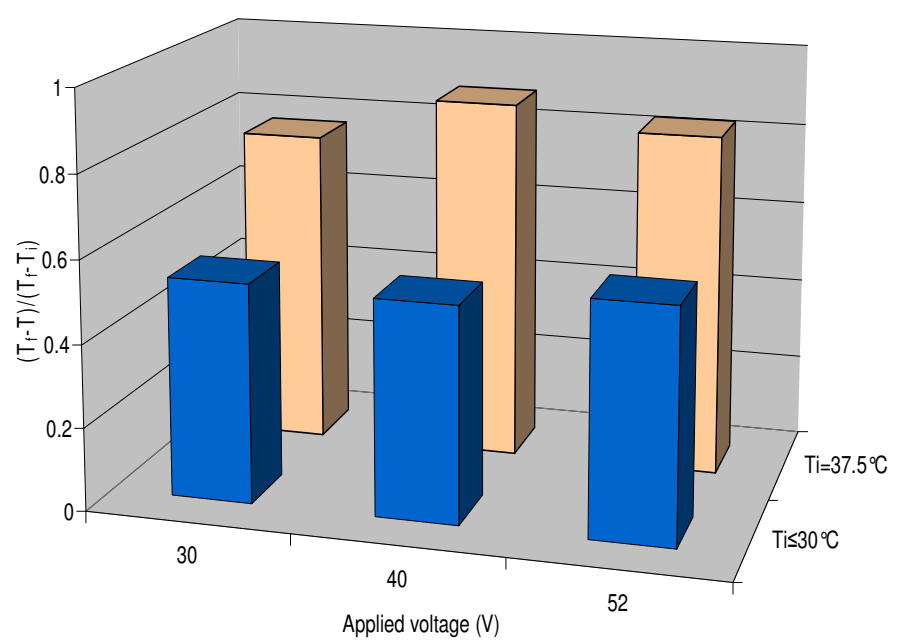

Fig. 3 Temperature gradient dimensionless characteristic across the scaffold at cooling $\left(\mathrm{T}_{\mathrm{i}}<30^{\circ} \mathrm{C}\right)$ and normal $\left(\mathrm{T}_{\mathrm{i}}=37^{\circ} \mathrm{C}\right)$ conditions after a 5 cycle RF treatment at $27.12 \mathrm{MHz}$ and three applied voltages. 
heating compared to an scaffold at an initial temperature of $37^{\circ} \mathrm{C}$. Thus, initial scaffold temperature of $<30^{\circ} \mathrm{C}$ results in smaller temperature gradient. Statistical analysis indicates that frequency and voltage have no significant effects ( $p_{-}$value $>0.01$ ) on the temperature gradient across the scaffold. Therefore, although RF heating rate strongly relies on the applied voltage and the frequency (see Eq. (3)), temperature gradient significantly depends on thermal properties such as scaffold thermal conductivity, specific heat capacity and initial temperature.

Multivariable statistical analyses indicated that frequency and the interaction between frequency and applied voltage have significant effects (p_value $<0.01$ ) on the tissue temperature elevation during cyclic RF treatments of the chitosan scaffold. Multiple regression analysis revealed that the tissue temperature elevation can be expressed as:

$$
\Delta T_{\text {tissue }}^{T_{0} \leq 30^{\circ} \mathrm{C}}=1.437+0.261 f-0.005 \mathrm{fV}
$$

where $\Delta T_{\text {tissue }}^{T_{0}<30^{\circ} \mathrm{C}}$ is the tissue temperature elevation from the initial temperature $\left(T_{0}\right)$ after 5 cycles of RF treatment (Fig. 2a) for a set point of $45^{\circ} \mathrm{C}, f$ is frequency in $\mathrm{MHz}$ and $V$ is voltage in Volt.

Figures. $4 \mathrm{a}$ and $\mathrm{b}$ depict predictions versus observations and the distribution of errors, respectively, associated with Eq. (4). As seen in Fig. $4 \mathrm{a}$, the coefficient of determination $\left(\mathrm{R}^{2}\right)$ of 0.81 and the normalized root mean squared error (NRMSE) of 0.13 indicate a good agreement between the predictions and observations. Figure $4 \mathrm{~b}$ reveals the random distribution of residual errors versus applied voltage indicating that errors are independent of the applied voltage. Eq. (4) is valid for frequency and applied voltage ranges of $3.5-27.12 \mathrm{MHz}$ and $30-52 \mathrm{~V}$, respectively. Statistical analyses showed that RF heating rate at the first $1 \mathrm{~mm}$ scaffold top below the deployed RF electrode was significantly (p_value $<0.01$ ) affected by the applied voltage and its interaction with frequency. $\mathrm{RF}$ heating rate can be given as:

$$
d T / d t=0.042 V-0.000255 f V-0.716
$$

where $d T / d t$ is the RF heating rate in ${ }^{\circ} \mathrm{Cs}^{-1}$.

Figure 5 illustrates the statistical measures of coefficient of determination, NRMSE and the distribution of residual of errors associated with Eq. (5). As seen in Fig. 5a, $\mathrm{R}^{2}$ of 0.85 and NRMSE of 0.11 indicate a good agreement between predictions and observations. Figure $5 b$ shows the random distribution of residuals of errors implying that the errors are independent of applied voltage. Eq. (5) is also valid for the ranges of frequency and voltage of 3.5-27.12 MHz and $30-52 \mathrm{~V}$, respectively. With respect to RF treatment of alginate scaffold at the
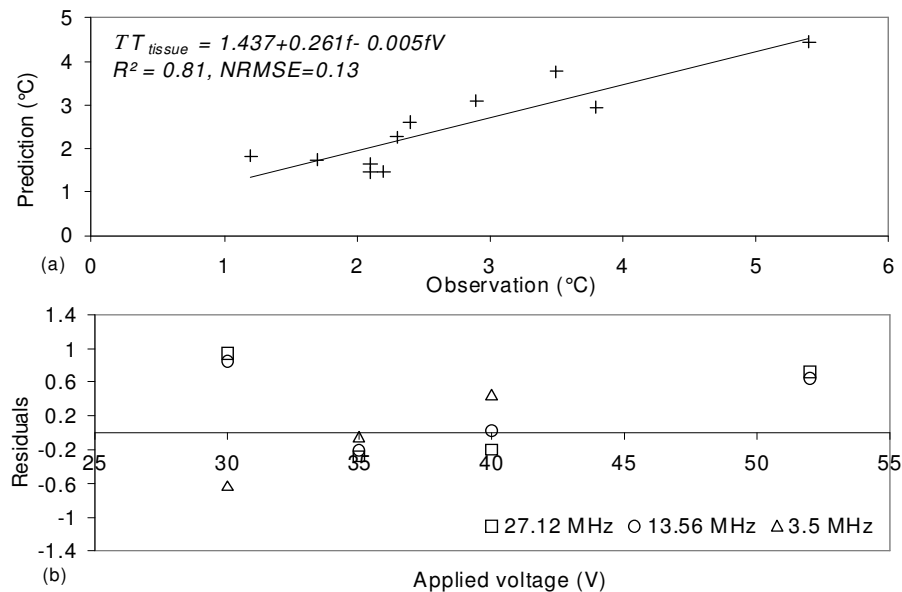

Fig. 4 Predictions $v s$. observations (a) and residual errors $v s$. applied voltage (b) of Eq. (4) for predicting tissue temperature rise during 5-cycle RF heating treatments within $3.5-27.12 \mathrm{MHz}$ and 30-52 V for a pre-cooled phantom and chitosan scaffold.

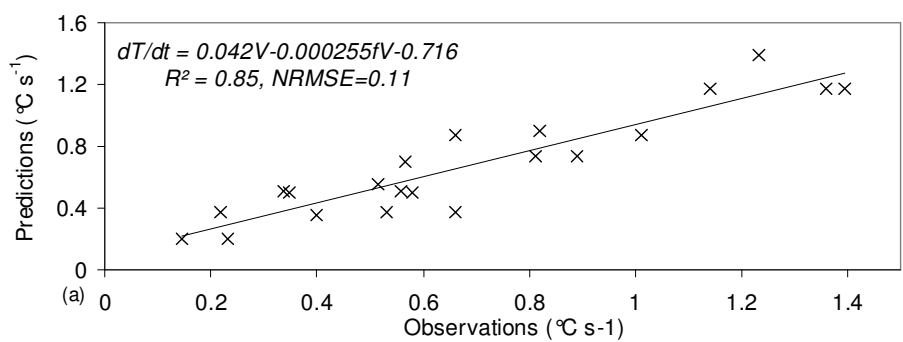

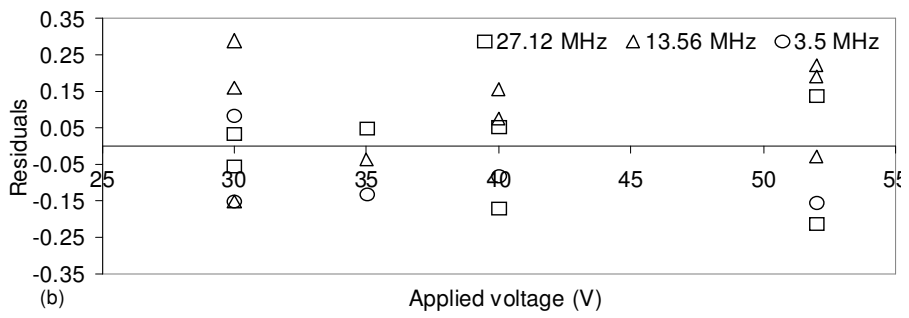

Fig. 5 Predictions versus observations (a) and residual errors (b) for predicting RF heating rate at $1 \mathrm{~mm}$ deep in chitosan scaffold during a 5-cycle RF heating treatment within 3.5-27.12 MHz and $30-52 \mathrm{~V}$.

normal body temperature of the phantom, statistical analyses indicate that phantom temperature changes is insignificant during the RF treatment; however, RF heating rate below the deployed RF electrode is not influenced by the frequency but linearly increases with the applied voltage as:

$d T / d t=0.029 \mathrm{~V}-0.501$

The $\mathrm{R}^{2}$ and NRMSE associated with Eq. (6) are 0.95 and 0.08 , respectively. The reason of insignificant effect of frequency on the heating rate of the alginate scaffold can be attributed to the low concentration of ionic compounds $(30 \mathrm{mM}$ calcium chloride) in the structure of the alginate. Low concentration of ions in the scaffold structure causes water molecules to have the major role in the electromagnetic based heating process rather than the ions. Since molecular flip-flop rotation is predominantly the main mechanism of heating of water, a high frequency in the range of microwave is needed rather than RF range. Therefore, for the alginate scaffold containing significant amount of water in its structure, the effect of amplitude of applied voltage on the heating rate dominates over the effect of frequency as implied by Eq. (6). Comparing RF heating in chitosan to
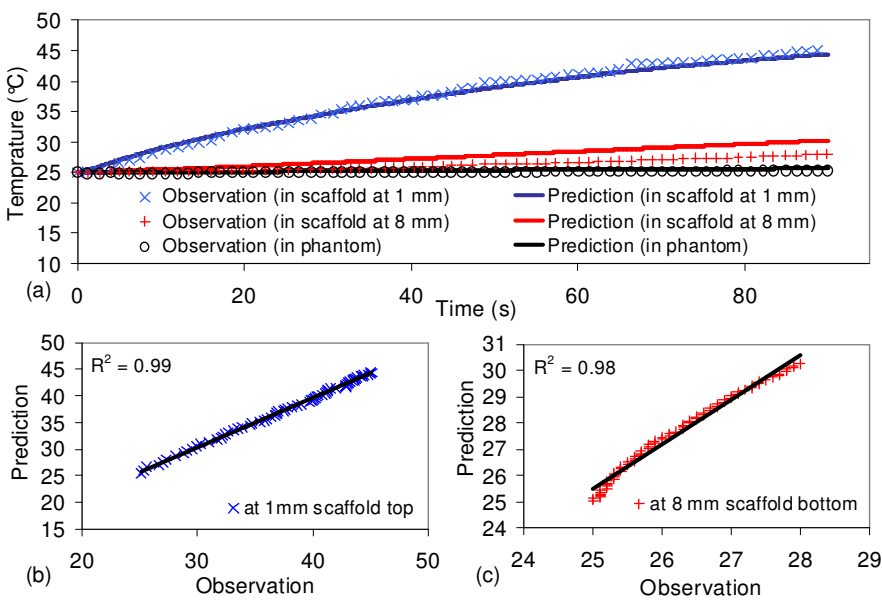

Fig. 6 Experimental and predicted values of the scaffold and phantom temperature vs. time (a); predictions vs. observations at $1 \mathrm{~mm}$ (b) and $8 \mathrm{~mm}$ deep (c) in chitosan scaffold for RF treatment at 13.56 $\mathrm{MHz}$ and $30 \mathrm{~V}$ 
that in alginate scaffolds reveals that at higher frequencies $(\sim 27.12$ $\mathrm{MHz}$ ) RF heating rate of chitosan scaffold is smaller than that of alginate scaffold; however, lower frequencies induce higher RF heating rate in chitosan than that in alginate scaffold.

Figure 6a depicts observed and predicted values of temperatures of the scaffold at 1 and $8 \mathrm{~mm}$ deep, and the phantom at $10 \mathrm{~mm}$ below the implanted scaffold versus the treatment time within the temperature ramping-up period at frequency and applied voltage of $13.56 \mathrm{MHz}$ and $30 \mathrm{~V}$, respectively. As seen in Fig. 6a, having a very good agreement with the measured data, predicted values by the finite element model indicate a rapid temperature increase at the top of the scaffold $1 \mathrm{~mm}$ deep below the deployed RF electrode. Figure $6 \mathrm{~b}$ shows the prediction versus observation of the temperatures at $1 \mathrm{~mm}$ deep from the scaffold top. The determination of coefficient of 0.99 indicates a very good agreement between prediction and observation. The gently increasing trend of the scaffold temperature at $8 \mathrm{~mm}$ deep from the scaffold top has been predicted by the model with a good agreement with measured data (Fig. 6a). Predicted values versus observed data, shown in Fig. 6c, indicates a good agreement with a determination of coefficient of 0.98 . In addition to the scaffold temperature, a very good agreement between phantom temperature predicted by the model and the observed values can be seen in Fig. 6 a.

Figure $7 \mathrm{a}$ depicts the simulation results from the finite element model for RF treatment of a chitosan scaffold at the frequency of 13.56 $\mathrm{MHz}$, applied voltage of $30 \mathrm{~V}$ at an initial temperature of $25^{\circ} \mathrm{C}$ for $95 \mathrm{~s}$ treatment. The temperatures of the scaffold top and bottom reach 45 and $27.5^{\circ} \mathrm{C}$, respectively, within $95 \mathrm{~s}$. The temperature gradient is associated with the RF electric field gradient across the scaffold. Despite the temperature gradient across the scaffold, a less temperature difference across the upper half of the scaffold indicates that if the scaffold length is reduced by half, more uniform temperature across the scaffold can be achieved. As seen in Fig. 7b, the temperature rise of the phantom adjacent to the scaffold is due to the heat conduction and RF heating; however, due to low RF electric field in the phantom compared

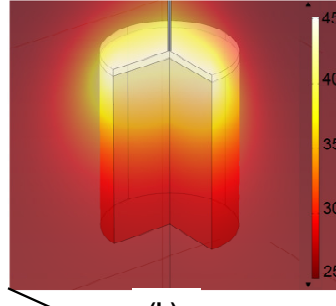

(b)

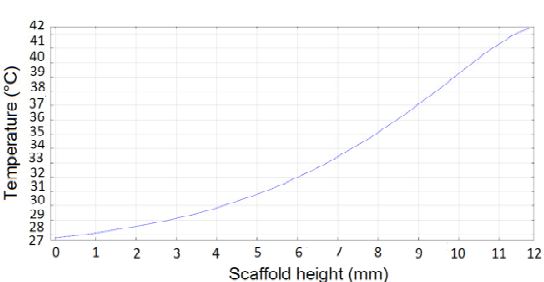

(c)

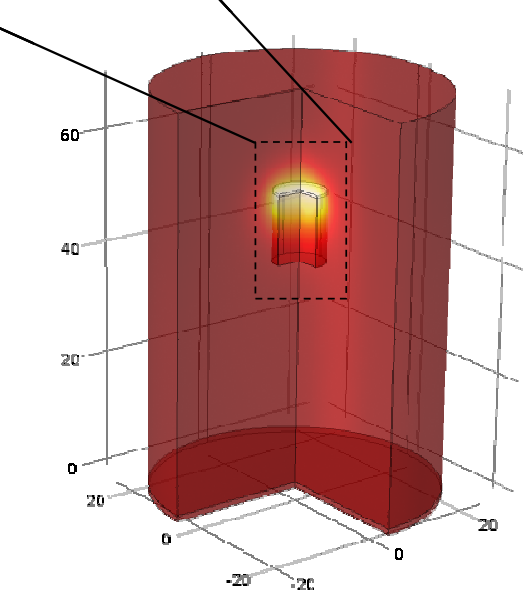

(a)

Fig. 7 Volumetric temperature distribution in tissue phantom and implanted scaffold (a), across the scaffold (b) and along the height of the scaffold (c) during a $95 \mathrm{~s}$ RF treatment at 13.56 $\mathrm{MHz}, 30 \mathrm{~V}$, at initial temperature of $25^{\circ} \mathrm{C}$ for $95 \mathrm{~s}$ treatment. to that in the scaffold, conduction heat transfer is the major cause of the temperature increase in the tissue phantom. Figure $7 \mathrm{c}$ illustrates the temperature of the phantom surrounding the scaffold within $10 \mathrm{~mm}$ distance. The temperature of the phantom adjacent to the upper part of the scaffold is higher than $37^{\circ} \mathrm{C}$ and varies from $38^{\circ} \mathrm{C}$ at $9.5 \mathrm{~mm}$ to $41.5^{\circ} \mathrm{C}$ at $12 \mathrm{~mm}$ scaffold height while the temperature of the phantom adjacent to the scaffold remains within 27 to $37^{\circ} \mathrm{C}$ indicating the influence of the RF heating on the tissue phantom is limited to the area adjacent to the first $3 \mathrm{~mm}$ high of the scaffold.

Figure 8a illustrates the variation of RF electric field with respect to the scaffold height. The maximum RF electric field of $2290 \mathrm{Vm}^{-1}$ exists at the scaffold top where the RF electrode has been deployed. Electric field decreases gently within the first $3 \mathrm{~mm}$ of the scaffold top and then is sharply declined across the rest of $10 \mathrm{~mm}$ of the scaffold. The variation of RF power dissipation density with the height of the scaffold has the same trend as the electric field (see Fig. 8b); however, a steeper decrease in power dissipation density can be seen from the scaffold height of $10 \mathrm{~mm}$ to the scaffold bottom. It is because of quadratic relationship between electromagnetic power loss and the electric filed (see Eq. (3)). Figure 8c illustrates the superposition of temperature distribution and the contours of applied voltage across the phantom as well as the scaffold. As it can be seen, higher voltage is
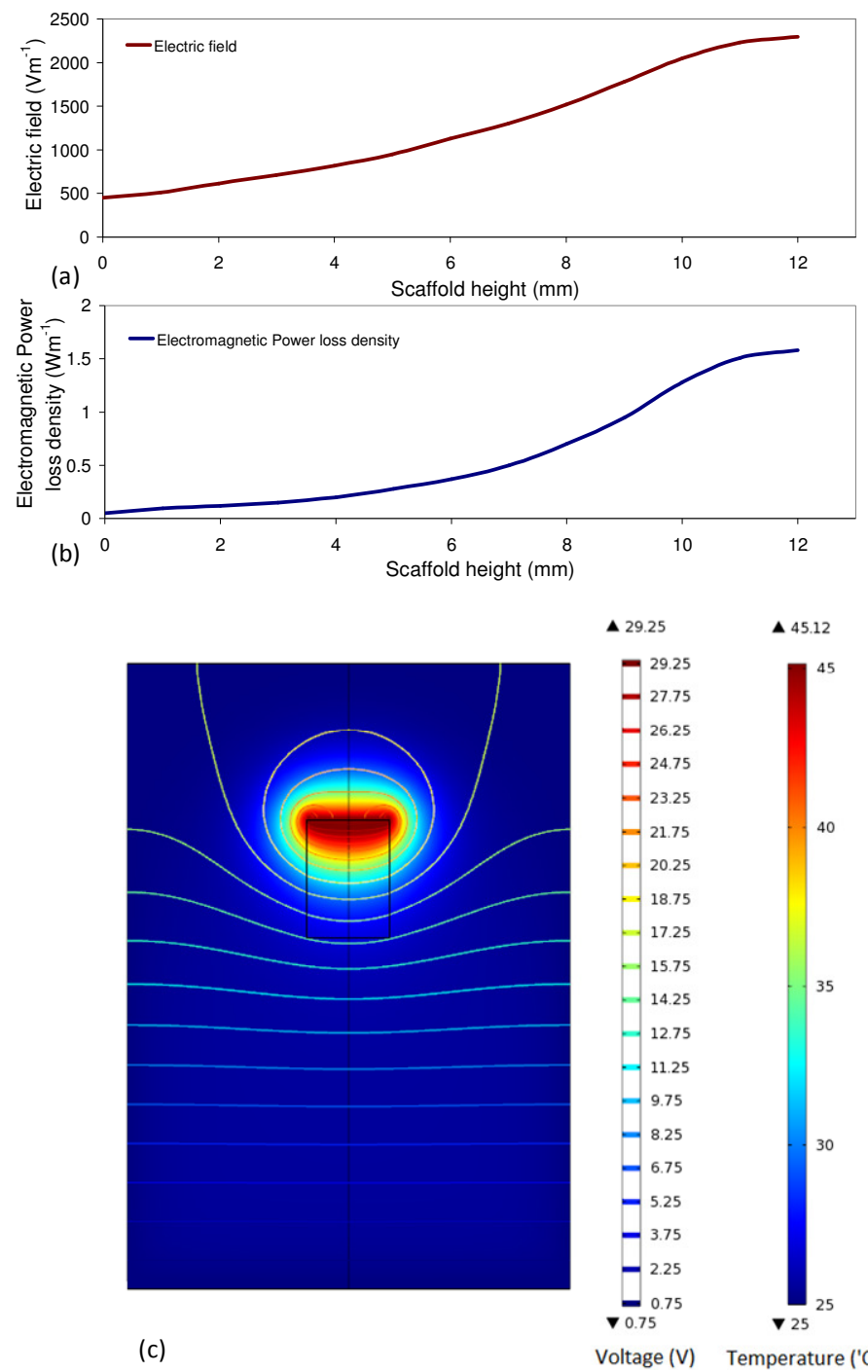

Fig. 8 Variation of electric field (a) and RF power dissipation density (b) with chitosan scaffold height; and temperature and applied voltage distribution (c) across the scaffold an phantom at 13.56 $\mathrm{MHz}$ and $30 \mathrm{~V}$. 
concentrated around the deployed electrode at the upper level of the scaffold and declines with the distance from the scaffold top. It is consistent with simulation results shown in Figs. 8a and b where higher voltages at the scaffold top causes higher electric field and consequently higher RF power loss leading to higher temperature. The applied voltage in the scaffold significantly drops from 30 to $20 \mathrm{~V}$ within $4 \mathrm{~mm}$ distance from the scaffold top and causes a significant decrease in RF heating within the lower half of the scaffold. It indicates that smaller scaffolds with heights of up to $5 \mathrm{~mm}$ can receive more uniform heating.

\section{CONCLUSIONS}

A minimally invasive RF heating was applied for volumetric heating of chitosan and alginate scaffolds implanted in a tissue mimicking phantom. Although experiments showed that a temperature gradient is unavoidably induced across the $12 \mathrm{~mm}$ scaffolds, a dimensionless temperature gradient criterion indicated that less temperature gradient is caused across the scaffold when RF treatment is performed at cooling environment condition $\left(<30^{\circ} \mathrm{C}\right)$. Simulation results also revealed that a relatively uniform RF heating was induced in the first $4 \mathrm{~mm}$ top of the scaffold indicating that smaller scaffolds can receive more uniform RF heating. RF heating significantly increased the temperature of the tissue phantom adjacent to the scaffold when phantom initial temperatures were below $30^{\circ} \mathrm{C}$. The applied voltage of $30 \mathrm{~V}$ caused the highest temperature elevation of $5.5^{\circ} \mathrm{C}$ in the tissue phantom adjacent to the scaffold; however, when the initial temperature was set at $37^{\circ} \mathrm{C}$, the applied voltage had no significant effect on the phantom temperature rise. Statistical analysis revealed that frequency and the interaction of frequency and voltage have significant effects on the temperature rise of the phantom surrounding the scaffold as well as RF heating rate of the chitosan scaffold. However, for the alginate scaffold frequency had no significant effect on RF heating rate. Since RF heating rate in chitosan scaffold depends on applied frequency and applied voltage, both variables should be taken into account for designing RF heating treatment of a chitosan scaffold; however, for alginate scaffold the variable of applied voltage will be reliable enough for adjusting the scaffold temperature induced by RF heating.

\section{ACKNOWLEDGEMENTS}

The authors appreciate Mr. Rlee Prokopishyn at the Department of Chemical and Biological Engineering, University of Saskatchewan for providing electrical facilities. We gratefully acknowledge NSERC for financial support and thank Dr. O.D. Baik for his financial contribution.

\section{NOMENCLATURE}

$\begin{array}{ll}C_{p} & \text { specific heat capacity }(\mathrm{J} / \mathrm{kg} \cdot \mathrm{K}) \\ E & \text { electric field }(\mathrm{V} / \mathrm{m}) \\ f & \text { frequency }(\mathrm{Hz}) \\ j & \sqrt{-1} \\ k & \text { thermal conductivity }(\mathrm{W} / \mathrm{m} \cdot \mathrm{K}) \\ Q & \text { radio frequency heating rate per unit volume }\left(\mathrm{W} / \mathrm{m}^{3}\right) \\ t & \text { time }(\mathrm{s}) \\ T & \text { temperature }(\mathrm{K}) \\ \Delta T & \text { tissue temperature rise }(\mathrm{K}) \\ V & \text { voltage }(\mathrm{V}) \\ \text { Greek Symbols } \\ \delta & \text { electrical conductivity }(\mathrm{S} / \mathrm{m}) \\ \varepsilon_{0}, & \text { relative permittivity of vacuum } \\ \varepsilon^{\prime}, & \text { relative dielectric constant } \\ \varepsilon & \text { relative dielectric loss factor } \\ \rho & \text { density }\left(\mathrm{kg} / \mathrm{m}^{3}\right) \\ \text { Subscripts } & \\ O & \text { initial condition } \\ R F & \text { associated with radio frequency }\end{array}$

tissue

associated with tissue

\section{REFERENCES}

Dhandayuthapani, B.,Yoshida, Y., Maekawa, T., and Sakthi Kumar D., 2011, "Polymeric Scaffolds in Tissue Engineering Application: A Review," International Journal of Polymer Science, ID 290602, 1-19. http://dx.doi.org/10.1155/2011/290602

Langer, R., and Vacanti, J.P., 1993, “Tissue engineering," Science, 260, 920-926.

http://dx.doi.org/10.1126/science.8493529

Van Blitterswijk, C.A., Thomsen, P., Hubbell, J., Cancedda, R., de Bruijn, J.D., Lindahl, A., Sohier, J. and Williams, D.F., 2008, Tissue Engineering, Academic Press, Elsevier.

Gopferich, A., 1996, "Mechanisms of polymer degradation and erosion," Biomaterials, 17, 103-114. http://dx.doi.org/10.1016/0142-9612(96)85755-3

Pietrzak, W.S., Barry, M.K., and Eppley, L., 2003, "The Influence of Temperature on the Degradation Rate of LactoSorb Copolymer," Journal of Craniofacial. Surgery, 14, 176-183. http://dx.doi.org/10.1097/00001665-200303000-00008

Pearce, J.A., 1986, Electrosurgery. John Wiley \& Sons Inc., NewYork.

Panescu, D., Whayne, J.G., Fleischman, S.D., Mirotznik, M.S., Swanson, D.K., and Webster, J.G., 1995, "Three-dimensional finite element analysis of current density and temperature distributions during radio-frequency ablation," IEEE Transaction on Biomedical Engineering, 42, 879-890.

http://dx.doi.org/10.1109/10.412649

Morady, F., 1999, " Radio-frequency ablation as treatment for cardiac arrhythmias," New England Journal of Medicine, 340, 534-544. http://dx.doi.org/10.1056/NEJM199902183400707

Li, K., Powell, N., Riley, R., Troell, R., and Guilleminault, C., 1998, "Radiofrequency volumetric tissue reduction for treatment of turbinate hypertrophy: a pilot study," Otolaryngology Head and Neck Surgery, $119,569-573$.

http://dx.doi.org/10.1016/S0194-5998(98)70013-0

Powell, N.B., Riley, R.W., Troell, R.J., Li, K., Blumen, M.B., and Guilleminault, C., 1998, "Radiofrequency volumetric tissue reduction of the palate in subjects with sleepdisordered breathing," Chest, 113, $1163-1174$

http://dx.doi.org/10.1378/chest.113.5.1163

Van Haesendonck, C., Sinnaeve, A., Willems, R., Vandenbulcke, F., and Stroobandt, R., 1998, "Biophysical and electrical aspects of radiofrequency catheter ablation," Acta Cardiological, 50, 105-115.

Keefe, M.W. Rasouli, A., Telenkov, A., Karamzadeh, A.M., Milner, T.E., Crumley, R. L., and Wong, B.J.F., 2003, "Radiofrequency cartilage reshaping," Archives of. Facial Plastic Surgery, 5, 46-52. http://dx.doi.org/10.1001/archfaci.5.1.46

Choi, C.T.M., and Konrad, A., 1991, "Finite-element modeling of the RF heating process," IEEE Transaction on Magnetics, 27, 4227-4230. http://dx.doi.org/10.1109/20.105034

McDonald, M., Lochhead, S., Chopra, R., and Bronskill, M.J., 2004, "Multimodality tissue-mimicking phantom for thermal therapy," Physics in Medicine and Biology, 49, 2767-2778. http://dx.doi.org/10.1088/0031-9155/49/13/001

Bu-Lin, Z., Bing, H., Sheng-Li, K., Huang, Y., Rong, W., and Jia, L., 2008, "A polyacrylamide gel phantom for radiofrequency ablation," International Journal of Hyperthermia, 24, 568-576. http://dx.doi.org/10.1080/02656730802104732 